Vietnam Journal of Mechanics, VAST, Vol.37, No. 3 (2015), pp. 205-216

DOI:10.15625/0866-7136/37/3/5939

\title{
TURBULENT BURNING VELOCITY IN COMBUSTION CHAMBER OF SI ENGINE FUELED WITH COMPRESSED BIOGAS
}

\author{
Bui Van Ga, Nguyen Van Dong, Bui Van Hung \\ The University of Danang, Da Nang, Vietnam \\ E-mail: buivanga@ac.udn.vn \\ Received March 04, 2015
}

\begin{abstract}
Turbulent burning velocity is the most important parameter in analyzing premixed combustion simulation of spark ignition engines. It depends on the laminar burning velocity and turbulence intensity in the combustion chamber. The first term can be predicted if one knows fuel composition, physico chemical properties of the fluid. The second term strongly depends on the geometry of the combustion chamber and fluid movement during the combustion process. One cannot suggest a general expression for different cases of engine. Thus, for accuracy modeling, one should determine turbulent burning velocity in the combustion chamber of each case of engine individually. In this study, the turbulent burning velocity is defined by a linear function of laminar burning velocity in which the proportional constant is defined as the turbulent burning velocity coefficient. This coefficient was obtained by analyzing the numerical simulation results and experimental data and this is applied to a concrete case of a Honda Wave motorcycle engine combustion chamber that fueled with compressed biogas. The results showed that the turbulent burning velocity coefficient in this case is around 1.3 when the average engine revolutions is in the range of $3000 \mathrm{rpm}$ to $6000 \mathrm{rpm}$ with biogas containing $80 \%$ Methane. We can then predict the effects of different parameters on the performance of the engine fueled with compressed biogas by simulation.
\end{abstract}

Keywords: Turbulent burning velocity, combustion simulation, biogas engine, spark ignition engine, biogas fuel.

\section{INTRODUCTION}

Biogas is a renewable energy which is interchangeable with natural gas. However, the problem which has existed until today is that all of the biogases yielded by different biogas digestion tanks are of low pressure, low specific gravity and large specific volume. The large quantity of $\mathrm{CO}_{2}$ present in biogas lowers its calorific value, flame velocity and flammability range compared with natural gas. Therefore, the biogas needs to be purified and compressed before it can be used in engines, especially in vehicle engines.

(C) 2015 Vietnam Academy of Science and Technology 
Vietnam is tropical country and waste from agriculture production is abundant to produce biogas. Besides, most of individual vehicles used in the country are motorcycles, so the application of biogas on this kind of vehicle will be a good way for fossil fuel saving and climate change mitigation. Research group GATEC of the University of Danang is the pioneer in developing technology of gaseous fuel application on the motorcycle [1]. The research is initially carried out on LPG fuel [2] and now it is shifted to compressed biogas $[3,4]$.

In order to convert a gasoline motorcycle engine to be a biogas engine, we should carry out a theoretical study on engine performance before doing technical modification. One of the most important unresolved problems of this study is the determination of the turbulent burning velocity in the combustion chamber of the engine. There is no consensus in literature whether the turbulent burning velocity is a characteristic quantity that can be defined unambiguously for different geometries.

Turbulent premixed flame propagation was first investigated by Damköhler (1940). He observed that the burning speed increases as Reynolds number increases and it was affected by two different scales of turbulence: low intensity $u^{\prime} / S_{L}$, large scale turbulence (weakly wrinkled flames); and high intensity $u^{\prime} / S_{L}$, small scale turbulence (strongly wrinkled flames) [5,6]. To develop mathematical models, Damköhler assumed that the flamelet propagates with a constant velocity in a one-dimensional plane. Thus, the only effect of turbulence is the wrinkling of the flame front which results in an increase in flame surface area but internal structure and $S_{L}$ are unchanged. The turbulent burning velocity was originally defined as follows $[7,8]$

$$
S_{T} / S_{L}=A_{T} / A_{L}
$$

where $S_{L}$ is the laminar burning velocity, $A_{T}$ is the wrinkled flame surface area and $A_{L}$ is the flow cross section area $[5,9,10]$. With such assumption, Damköhler developed the first following model

$$
\frac{S_{T}}{S_{L}}=1+\frac{u^{\prime}}{S_{L}}
$$

where $u^{\prime}$ is the turbulence intensity.

The high pressure conditions have an effect on the thermo-physical properties of the air-fuel mixture and the turbulent structures become finer as the pressure increases [11], as well as a decrease of laminar burning velocity and the thickening of the laminar flame front [12]. Kobayashi [11] has reported an increasing in turbulent burning velocity as pressure increases and he suggested empirical correlation for methane/air flames

$$
\frac{S_{T}}{S_{L}}=2.9\left[\left(\frac{P}{P_{o}}\right)\left(\frac{u^{\prime}}{S_{L}}\right)\right]^{0.38},
$$

where $P$ is the operating pressure and $P_{o}$ is the atmospheric pressure.

In these above expressions, laminar burning velocity $S_{L}$ depends on the physico chemical characteristics of the mixture and it can be calculated if one knows the details of rate of chemical reactions taking place in the combustion process. In general, this data is established for mixture of pure fuel and air. M. Elia et al. [13] found a relationship between laminar burning velocity and physical-chemical behavior of the mixture before 
combustion. R. Stone and A. Clarke [14] conducted experiments to determine the laminar burning velocity $\mathrm{CH}_{4}$-air mixture diluted by $\mathrm{CO}_{2}$ atmosphere. Laminar burning velocity of methane-air mixture can be established by empirical expressions as follows

$$
S_{L}=0.366 T^{1.42} P^{-0.297}(\mathrm{~m} / \mathrm{s}),
$$

where $T=T_{u} / T_{o}$ is dimensionless temperature and $P=P_{u} / P_{o}$ is dimensionless pressure.

According to Rallis and Garforth [15], laminar burning velocity of methane-air stoichiometric mixture can be expressed by

$$
S_{L}=S_{L, o} T^{\alpha_{o}}
$$

where $\alpha_{o}$ is in interval of 1.37 and 2.33 .

Biogas-air mixture could be considered as methane-air mixture diluted by $\mathrm{CO}_{2}$. Laminar burning velocity in this case is presented in [16]. Thus, with a given cylinder pressure, mixture temperature, and composition of biogas, we can calculate laminar burning velocity. Turbulent burning velocity depends not only on laminar burning velocity but also on fluid movement in the combustion chamber. In this work, we simplify the relationship between turbulent burning velocity and laminar burning velocity by an assumption of $S_{T}=f_{f} S_{L}$. We try to determine the turbulent burning velocity coefficient $f_{f}$ in the combustion chamber of a Honda Wave motorcycle engine fueled with compressed biogas.

In view of the above, the specific aims of this study were defined as follows:

(1) To carry out experimental measurement of the indicated cylinder pressure

(2) To carry out simulation calculation with identical experimental condition

(3) To compare the simulation results with experimental data in order to determine the turbulent burning velocity coefficient in the combustion chamber.

\section{METHOD OF STUDY}

\subsection{Experimental setup}

The experiment was conducted at the research laboratory of internal combustion engines of Hanoi University of Science and Technology. The experimental facilities include a CD20" Chassis Dynamometer Test Bed AVL for motorcycles that is controlled by Zoller software. Equipment Indiset 620 including a computer with the IndiWin620 software for data acquisition from different sensors such as the pressure in the combustion chamber, detonation, advance spark timing angle, TDC position, etc. The cylinder pressure is obtained by means of a piezoelectric transducer. A synchronization optical crank angle encoder $364 \mathrm{C}$ was used to acquire the cylinder pressure on the basic of crank angle rather than the time. Operational parameters such as speed, acceleration and power of the motorcycle are displayed on the control screen. Experimental data is treated by Concerto software. A schematic layout of the experimental facilities is shown in Fig. 1. Fig. 2 illustrates pictures of instruments for biogas motorcycle testing at the laboratory.

The following mass flow rates were determined: (1) air, by measurement of the pressure drop across an orifice; (2) biogas, by means of rotameters; (3) petrol, by weighing and timing. Hence, we can estimate the equivalence ratio of the mixture. 

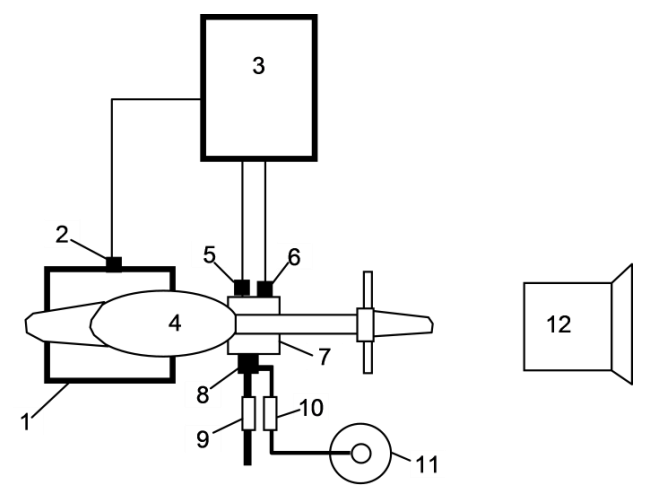

Fig. 1. Experimental facilities layout 1. AVL motorcycle test bed, 2. Force traducer; 3. Control system, 4. Honda Wave motorcycle, 5. Cylinder pressure sensor, 6. Optical decoder for engine speed, 7. Engine, 8. GATEC 25 gas carburetor, 9. Air flowmeter, 10. Biogas flowmeter, 11. Compressed biogas cylinder, 12. Ventilator
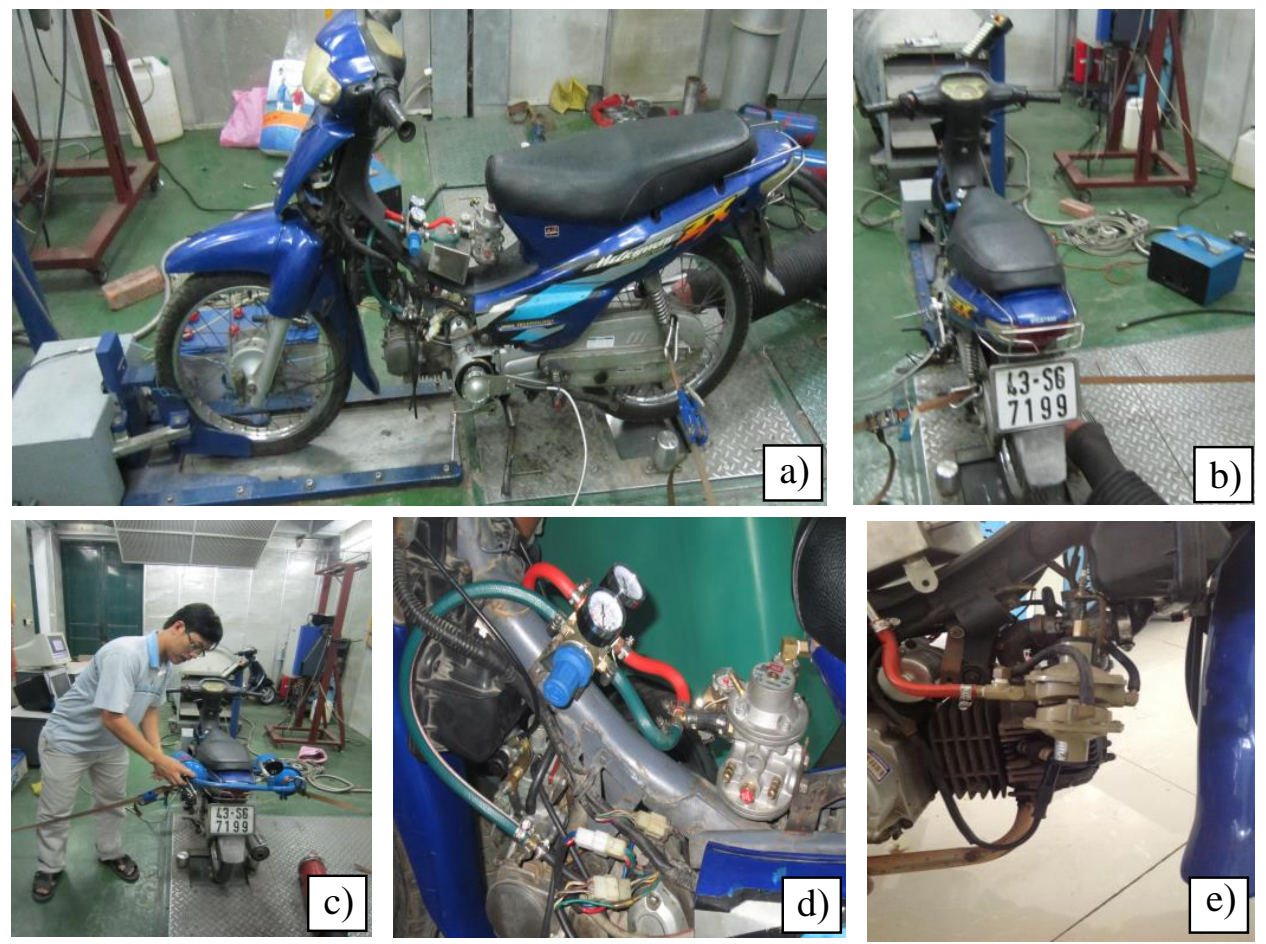

Fig. 2. Practical instruments for biogas motorcycle testing: Installing biogas motorcycle on CD20" Chassis Dynamometer Test Bed AVL (a and b); Installing biogas cylinders (c); Pressure regulators (d) and GATEC 25 biogas carburetor 
Compressed biogas from pressure cylinders is supplied to the engine with help of conversion kit GATEC25 [17]. This is a special gas carburetor that ensures stable equivalence ratio at any regime of the engine which was fitted to the engine's air intake upstream of the petrol carburetor. Biogas flow rate could be adjusted by a needle valve in the gas inlet port. A pointer and scale arrangement indicating percentage of full throttle opening was retrofitted to the butterfly valve. The fuel was inducted into the throat of the venturi and the mixture flow rate was controlled by the throttle.

\subsection{Numerical simulation}

The combustion of biogas-air mixture in the combustion chamber of the engine is simulated using Ansys FLUENT computational fluid dynamics software. The structural and operational parameters of the engine are introduced into the program via the dynamic mesh option. Thermodynamic properties of the working fluid are set in PrePDF table integrated into the FLUENT software. Turbulent combustion is simulated via the $k$ $\varepsilon$ turbulence model and the partially premixed combustion model with laminar burning velocity $S_{L}$ which is determined empirically with fuel containing two major components, which are $\mathrm{CH}_{4}$ and $\mathrm{CO}_{2}$. The turbulent burning velocity is determined via $S_{L}$ and a given turbulent burning velocity coefficient by simplified relationship $S_{T}=f_{f} S_{L}$.

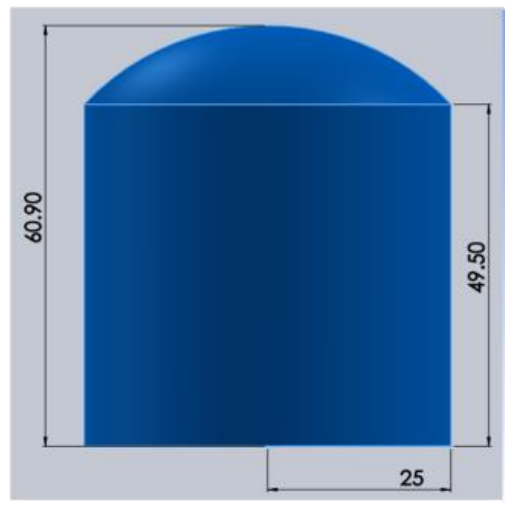

(a)

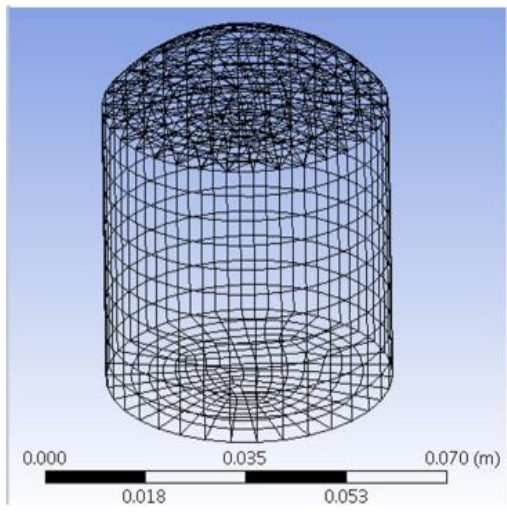

(b)

Fig. 3. Dimension of cylinder and combustion chamber of Honda Wave motorcycle engine (a) and meshing of calculating space (b)

Fig. 3a illustrates the dimensions of the combustion chamber and cylinder of a typical single-cylinder Honda Wave motorcycle engine. It is a four-stroke engine with bore, $\mathrm{D}=50 \mathrm{~mm}$, stroke, $\mathrm{S}=49.50 \mathrm{~mm}$, and a rated power output of $5.1 \mathrm{~kW}$ at 8000 $\mathrm{rpm}$. The compression ratio of the engine is 9:1. The ignition system is powered by a CDI with an essentially fixed spark timing of $30^{\circ}$ before TDC. The combustion chamber of the engine is hemispherical in shape with a bowl-shaped cylinder head and a flat piston top.

Fig. $3 \mathrm{~b}$ shows the meshing of the computational space. To avoid the occurrence of negative volume elements caused by element deformation during piston displacement, the combustion chamber and the cylinder are meshed separately. 


\section{RESULTS AND DISCUSSION}

\subsection{Simulation results}

In the following section, the turbulent burning velocity coefficient is fixed at $f_{f}=$ 1.3 and then we predict the effects of the equivalence ratio and composition of biogas to the performance of the Honda Wave motorcycle engine. The effect of advance spark timing angle and engine speed has been published in previous works [18].

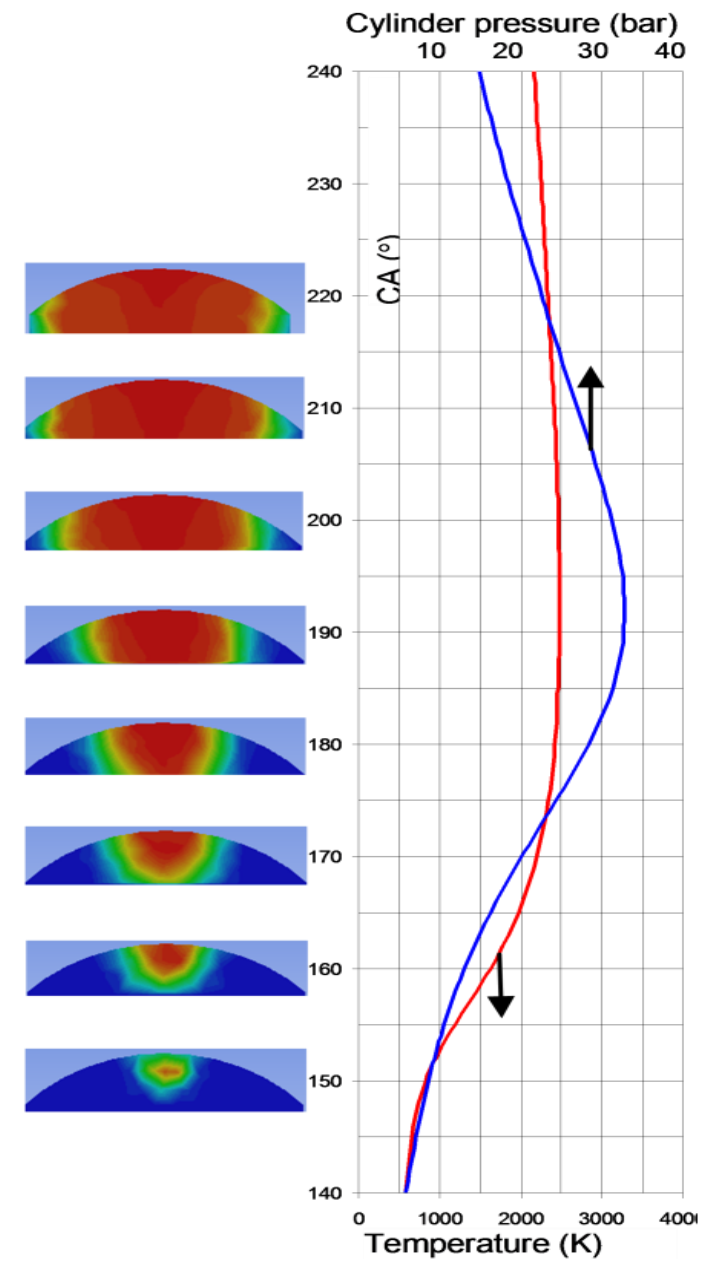

Fig. 4. Variation of cylinder pressure, fluid temperature and $\mathrm{CH}_{4}$ concentration during combustion process of Honda Wave motorcycle engine fueled with biogas containing $85 \% \mathrm{CH}_{4}$

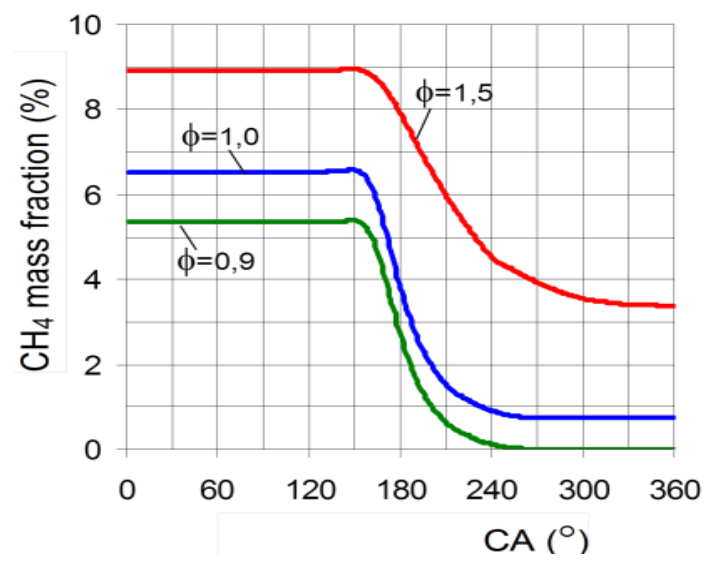

(a)

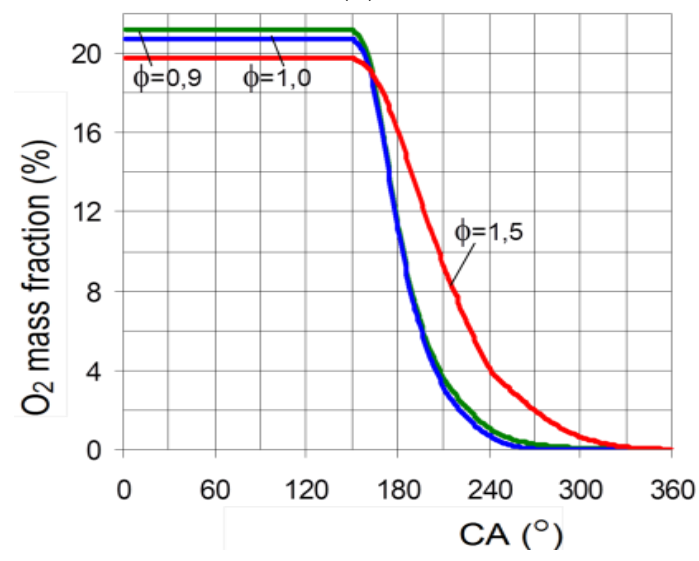

(b)

Fig. 5. Variation of $\mathrm{CH}_{4}$ mass fraction (a) and $\mathrm{O}_{2}$ mass fraction (b) with crank angle during combustion $\left(n=3000 \mathrm{rpm}, \varphi_{s}=30^{\circ}\right.$, biogas containing $85 \% \mathrm{CH}_{4}, \phi=1$ )

Fig. 4 presents flame propagation at different crank angle and variation of temperature and pressure as result in the combustion chamber of the engine fueled with biogas 
containing $85 \% \mathrm{CH}_{4}$. We observe that flame front initially has a spherical shape and then it is deformed during spreading out in space of the combustion chamber away from the spark plug. A peak of pressure occurred at approximately 13 degrees after TDC and a peak of combustion temperature occurred at about 5 degrees later.

Figs. 5a and Fig. 5b introduce the variation of concentrations of $\mathrm{CH}_{4}$ and $\mathrm{O}_{2}$ in the combustion chamber with engine revolution speed of $3000 \mathrm{rpm}$, advance spark timing angle $30^{\circ}$ and equivalence ratio of $0.9,1.0$, and 1.5 . The higher the slope of the curve, the higher rate of fuel and oxidizer consumption. The results show that the highest fuel consumption rate is achieved at an equivalence ratio of $\phi=1$. When $\phi=0.9$, in the early phase of combustion, fuel consumption rate is not different with $\phi=1$ case but at the end of combustion process, the difference is more evident on $\mathrm{O}_{2}$ consumption curve. The slope of the curve for variation of $\mathrm{CH}_{4}$ and $\mathrm{O}_{2}$ with $\phi=1.5$ is significantly lower than the previous two cases.

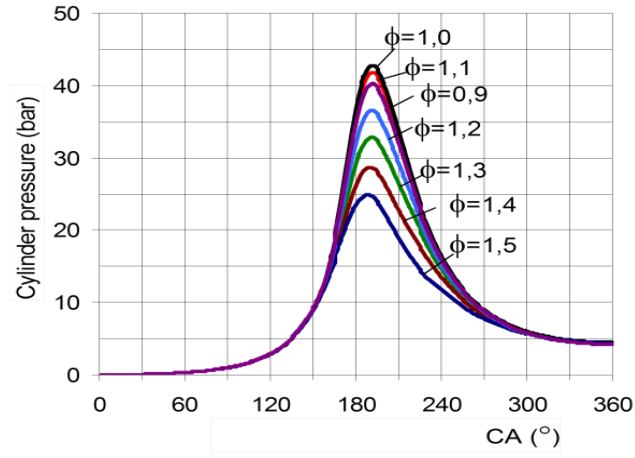

(a)

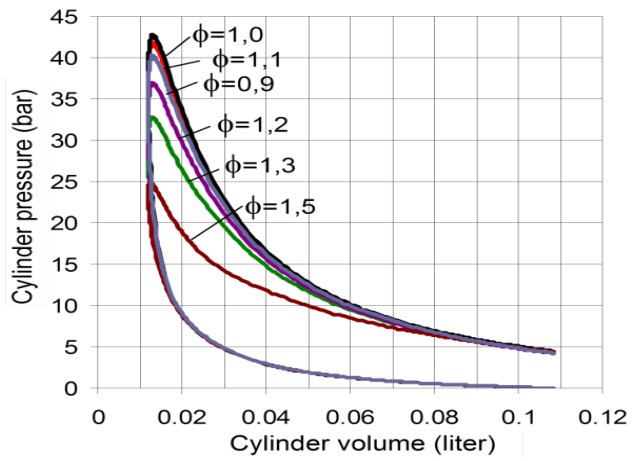

(b)

Fig. 6. Effect of equivalence ratio to cylinder pressure diagrams (a) and cycle work diagrams (b) $\left(n=3000 \mathrm{rpm}, \varphi_{s}=30^{\circ}\right.$, biogas containing $\left.85 \% \mathrm{CH}_{4}\right)$

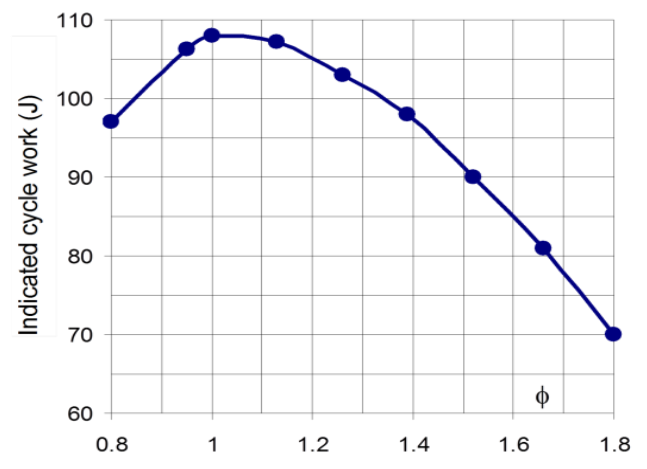

Fig. 7. Variation of indicated cycle work with equivalence ratio ( $n=3000 \mathrm{rpm}, \varphi_{\mathrm{s}}=30^{\circ}$, biogas containing $85 \% \mathrm{CH}_{4}$ ) 
Figs. $6 \mathrm{a}$ and $6 \mathrm{~b}$ show the indicated cylinder pressure diagrams and the indicated cycle work diagrams for various equivalence ratios with engine revolution speed of 3000 rpm, advance spark timing angle of $30^{\circ}$ and biogas fuel containing $85 \% \mathrm{CH}_{4}$. The indicated cycle work of the engine is represented by the area bounded in the compression and expansion curves. Variation of the indicated cycle work versus $\phi$ is presented in Fig. 7. We observe that the indicated cycle work of the engine reaches its maximum value with $\phi$ in range from 1 to 1.1 corresponding to the zone with the highest value of combustion rate.

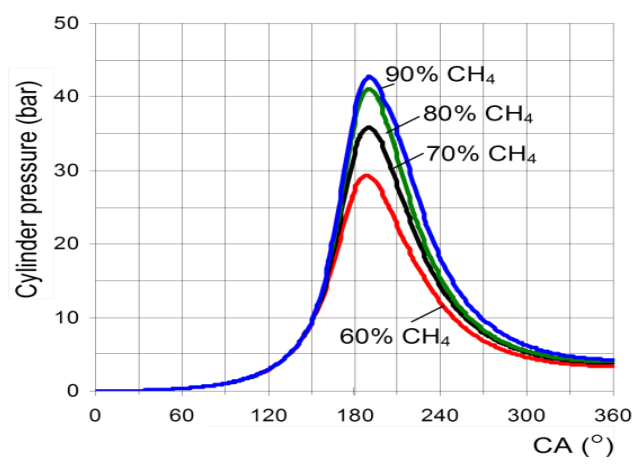

(a)

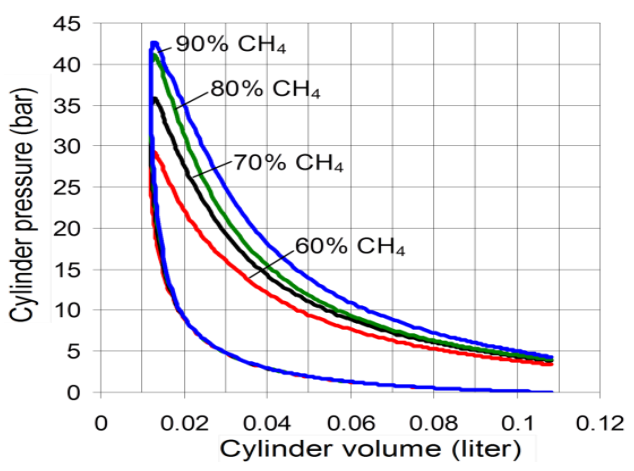

(b)

Fig. 8. Effect of $\mathrm{CH} 4$ composition in biogas to cylinder pressure diagram (a) and to indicated cycle work diagrams (b) $\left(n=5000 \mathrm{rpm}, \varphi_{s}=35^{\circ}, \phi=1\right)$

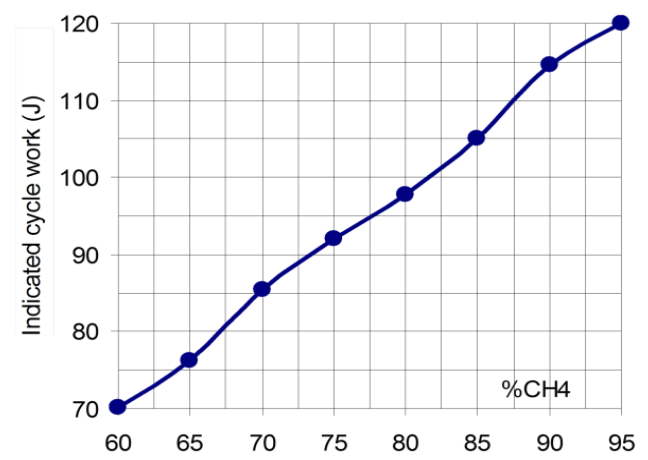

Fig. 9. Variation of indicated cycle work with $\mathrm{CH} 4$ composition in biogas

$$
\left(n=5000 \mathrm{rpm}, \varphi_{s}=35^{\circ}, \phi=1\right)
$$

The following section presents the effects of biogas components on engine performance. The calculations are carried out with advance spark timing angle $35^{\circ}$, equivalence ratio $\phi=1$ and engine speed $n=5000 \mathrm{rpm}$. Biogas fuel contains $60 \%, 70 \%$, and $80 \% \mathrm{CH}_{4}$. Figs. $8 \mathrm{a}$ and $8 \mathrm{~b}$ show the variation of indicated pressure and indicated cycle work versus $\mathrm{CH}_{4}$ component in biogas as engine runs at $5000 \mathrm{rpm}$, advance spark timing angle of $35^{\circ}$, 
equivalence ratio $\phi=1$. When the concentration of $\mathrm{CH}_{4}$ in biogas increases, the maximum pressure of the engine is increased leading to an increasing of the indicated cycle work. Fig. 8a illustrates that at the fixed equivalence ratio, the combustion chamber peak pressure decreases gradually with the introduction of carbon dioxide into the mixture, due to the lower reactive charge inducted and the thermal release rate with the increase of $\mathrm{CO}_{2}$ giving rise to the above observations. The result shows that the indicated cycle work increases linearly with $\mathrm{CH}_{4}$ composition in biogas, as shown in Fig. 9.

\subsection{Experimental measurements}

The experiment was carried out firstly with gasoline RON92 and then mainly with compressed biogas. The full load curves of the engine were established as the throttle valve was fully opened. Figs. 10a and 10b present the comparison of the indicated cylinder pressure and the indicated work diagram of the Honda Wave motorcycle engine fueled with gasoline RON92 and fueled with biogas containing $80 \% \mathrm{CH}_{4}$ at the same operating conditions: engine revolution speed of $3000 \mathrm{rpm}$, stoichiometric mixture, advance spark timing angle $30^{\circ}$. The results showed that when using biogas, the peak cylinder pressure is 35bar which is lower than when gasoline was used (57bar). When switching from gasoline to biogas, the maximum cylinder pressure drops and it can be explained by two reasons: firstly, volume efficiency decreases because of gas fuel, and secondly, reduction in burning velocity and heat value of the mixture caused by the dilution of $\mathrm{CH}_{4}$ with $\mathrm{CO}_{2}$ in biogas. As a result, the indicated cycle work of the engine fueled with compressed biogas containing $80 \% \mathrm{CH}_{4}$ presents only $72 \%$ value of that fueled with gasoline RON92. It confirms the observation of Jawurek et al. The authors observed that the engine operates smoothly on gases containing up to $23 \% \mathrm{CO}_{2}$, slightly noisily at $31 \% \mathrm{CO}_{2}$ and harshly at $42 \% \mathrm{CO}_{2}$. Maximum power output was $17 \%$ lower with $\mathrm{CH}_{4}$ than with petrol. Increased $\mathrm{CO}_{2}$ content of the gas led to further losses, with a $45 \%$ loss (compared with petrol) at $41 \% \mathrm{CO}_{2}$ [19].

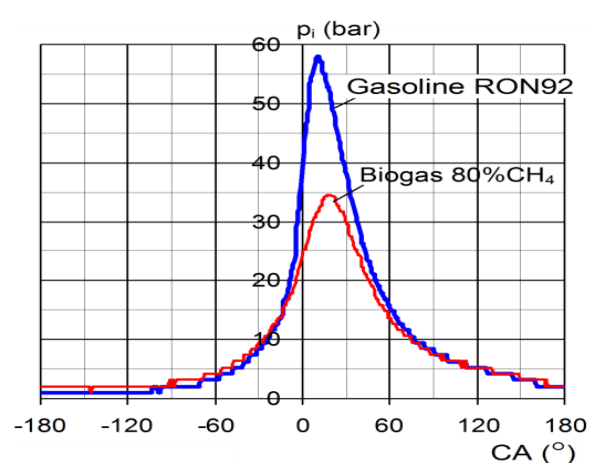

(a)

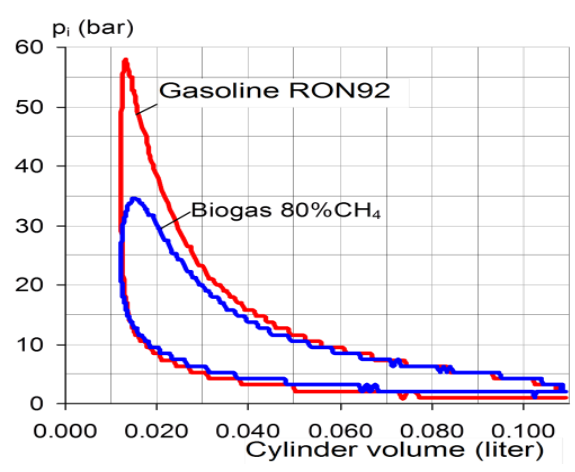

(b)

Fig. 10. Comparison of cylinder pressure diagrams (a) and indicated cycle work diagrams (b) of Honda Wave motorcyce engine fueled with gasoline RON92 and with biogas containing $80 \% \mathrm{CH}_{4}$ 
The presence of carbon dioxide in the biogas reduces the burning velocity which ultimately affects the performance of the engine. According to Bari [20], engine power is lower when compared with that obtained in a diesel engine fumigated with natural gas, while Neyloff found out that $\mathrm{HC}, \mathrm{NO}_{x}$, and $\mathrm{CO}$ emissions from a CFR engine were reduced [21]. Though the quantity of fuel admitted can be increased to ensure approximately the same thermal loading [22], the indicated power output and cyclic variation generally deteriorate with the increased proportion of carbon dioxide mixed with the methane.

In the following section, we compare the indicated cylinder pressure given by the simulation model and the experiment at different speed regimes in order to identify the turbulent burning velocity coefficient. Compressed biogas contains $85 \% \mathrm{CH}_{4}$, advance spark timing angle of the engine is fixed at $27^{\circ}$, equivalence ratio $\phi=1$ at full throttle opening. Using each experimental result, we adjust the computational model's pressure diagram to match the experimental data.

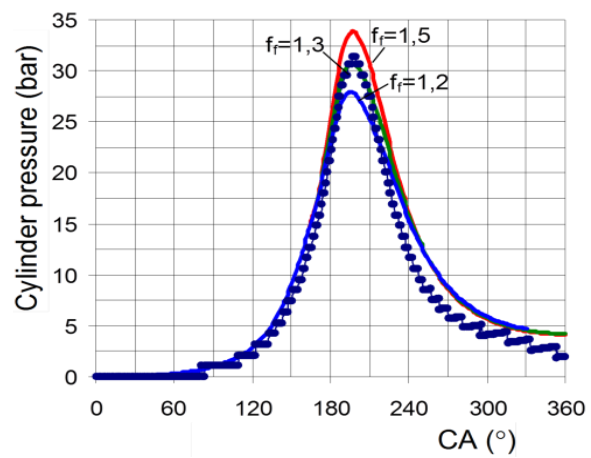

(a)

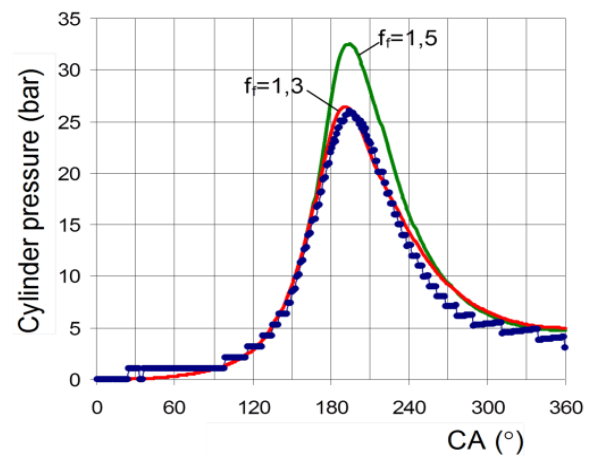

(c)

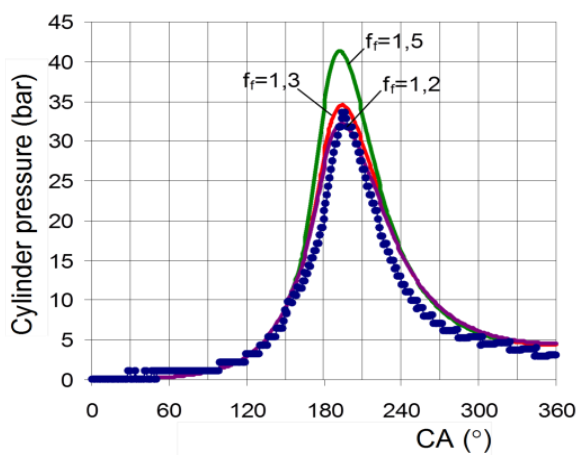

(b)

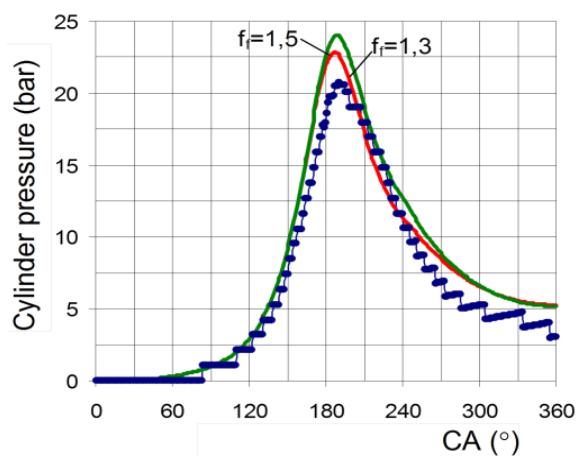

(d)

Fig. 11. Comparison of cylinder pressures given by simulation and by experiment $\left(\varphi_{s}=27^{\circ}\right.$, biogas containing $\left.85 \% \mathrm{CH}_{4}, \phi=1\right)$

The comparison of indicated pressures given by experiment and by simulation model at an engine revolution speed of $3000 \mathrm{rpm}$ and $3620 \mathrm{rpm}$ is shown in Figs. 11a 
and $11 \mathrm{~b}$ with three turbulent burning velocity coefficient $f_{f}$ of $1.2,1.3$ and 1.5 . The results showed that with the turbulent burning coefficient $f_{f}=1.3$, the indicated pressures given by simulation are close to the experimental data. This coefficient is also consistent with the case of $n=4070 \mathrm{rpm}$ (Fig. 11c). As the engine revolution speed increases to $5360 \mathrm{rpm}$, maximum indicated pressure decreases rapidly. If using the same coefficient $f_{f}=1.3$ as the above cases, the maximum indicated cylinder pressure given by the computational model is higher than the experimental results by approximately $10 \%$, as shown in Fig. 11d.

\section{CONCLUSIONS}

The results of this study allow us to draw the following conclusions:

1. The turbulent burning velocity coefficient of biogas-air mixture in the combustion chamber of a Honda Wave motorcycle engine fueled with compressed biogas containing $85 \% \mathrm{CH}_{4}$ is approximately 1.3 .

2 . The indicated cycle work of a $110 \mathrm{cc}$ Honda Wave motorcycle engine reduces $28 \%$ when switching from gasoline RON92 to compressed biogas containing $80 \% \mathrm{CH}_{4}$.

3 . For a given equivalence ratio, the indicated cycle work of the engine increases almost linearly with $\mathrm{CH}_{4}$ composition in the biogas fuel.

\section{REFERENCES}

[1] www.dongcobiogas.com/en/.

[2] B. V. Ga, T. V. Nam, and T. T. H. Tung. LPG motorcycles. In International conference on automotive technology. Science and Technics Publishing House, (2002), pp. 1-6.

[3] B. V. Ga, T. V. Nam, and T. T. H. Tung. Motorcycle fueled by compressed biogas. In International Forum on Strategic Technologies, Ho Chi Minh City, (2009). pp. 17-24.

[4] B. V. Ga, T. T. H. Tung, and N. V. Dong. Simulation and experimental studies of performance of 110cc motorcycle engine running on biogas. In The 4" AUN/SEED-Net Regional Conference in Mechanical and Aerospace Technology, (2012), pp. 182-190.

[5] K. K. Kuo. Principles of combustion. John Wiley \& Sons, Inc, New York, (1986).

[6] G. R. Inger. Scaling nonequilibrium-reacting flows: The legacy of Gerhard Damköhler. Journal of Spacecraft and Rockets, 38, (2), (2001), pp. 185-190.

[7] Ö. L. Gülder. Turbulent premixed flame propagation models for different combustion regimes. In Symposium (International) on Combustion, (1991), pp. 743-750.

[8] N. Peters. The turbulent burning velocity for large-scale and small-scale turbulence. Journal of Fluid mechanics, 384, (1999), pp. 107-132.

[9] S. R. Turner. An introduction to combustion, concepts and applications. McGraw Hill Companies, Inc., U.S.A., 2nd edition, (2000).

[10] O. L. Gulder and G. J. Smallwood. Do turbulent premixed flame fronts in spark-ignition engines behave like passive surfaces? SAE Transactions - Journal of Engines, 109, (2001), pp. 18231832.

[11] H. Kobayashi. Experimental study of high-pressure turbulent premixed flames. Experimental Thermal and Fluid Science, 26, (2), (2002), pp. 375-387.

[12] F. Halter, C. Chauveau, and I. Gökalp. Investigations on the flamelet inner structure of turbulent premixed flames. Combustion Science and Technology, 180, (4), (2008), pp. 713-728. 
[13] M. Elia, M. Ulinski, and M. Metghalchi. Laminar burning velocity of methane-air-diluent mixtures. Journal of Engineering for Gas Turbines and Power, 123, (1), (2001), pp. 190-196.

[14] R. Stone, A. Clarke, and P. Beckwith. Correlations for the laminar-burning velocity of methane/diluent/air mixtures obtained in free-fall experiments. Combustion and Flame, 114, (3), (1998), pp. 546-555.

[15] B. Galmiche, F. Halter, F. Foucher, and P. Dagaut. Effects of dilution on laminar burning velocity of premixed methane/air flames. Energy \& Fuels, 25, (3), (2011), pp. 948-954.

[16] S. P. Marshall, R. Stone, C. Hegheş, T. J. Davies, and R. F. Cracknell. High pressure laminar burning velocity measurements and modelling of methane and n-butane. Combustion Theory and Modelling, 14, (4), (2010), pp. 519-540.

[17] B. V. Ga. 3-valve system for gas fuel supplying to LPG/gasoline motorcycle. Panent No. 6643, National Intellectual Property Office, (2007).

[18] B. V. Ga, T. V. Nam, T. T. H. Tung, and N. V. Dong. Simulation of effects of operation parameters to combustion process of SI engine fueled with biogas. Vietnam Review of Mechanics, 1, (2011), pp. 4-9. (in Vietnamese).

[19] H. H. Jawurek, N. W. Lane, and C. J. Rallis. Biogas/petrol dual fuelling of SI engine for rural third world use. Biomass, 13, (2), (1987), pp. 87-103.

[20] S. Bari. Effect of carbon dioxide on the performance of biogas/diesel duel-fuel engine. Renewable Energy, 9, (1), (1996), pp. 1007-1010.

[21] S. Neyeloff and W. Gunkel. Performance of a CFR engine burning simulated anaerobic digester's gas. ASAE Publication, 2, (1981), pp. 324-329.

[22] G. Karim and I. Wierzba. Methane-carbon dioxide mixtures as a fuel. Technical report, SAE Technical Paper, (1992). 